\title{
Uma nova estratégia de desenvolvimento sustentável: alguns pontos para o debate
}

Fábio Dória Scatolin*

Marcelo Costa Misael ${ }^{* *}$

"Somos um povo, uma nação e uma economia que precisa reinventar-se"

(Antonio Barros de Castro)

\begin{abstract}
RESUMO - O presente artigo discute as diferentes estratégias de desenvolvimento adotadas pelos países emergentes desde a segunda grande guerra até 2008 e uma nova estratégia de desenvolvimento para os países de industrialização retardatária. Em uma primeira seção o objetivo é entender as características centrais destas estratégias, com destaque para seus objetivos e instrumentos. $\mathrm{O}$ intuito é de auxiliar a entender os pontos centrais destas estratégias bem como seus limites. Na sequência, são discutidos alguns elementos importantes para a constituição de uma nova estratégia de desenvolvimento para os países emergentes pós-crise financeira, tendo como pressuposto a sustentabilidade da estratégia de desenvolvimento. Nesta seção, dois conceitos são introduzidos; o de dissociação dos recursos e de dissociação de impactos ambientais (decoupling). A seguir, o conceito de salto à frente (leapfrogging), diretamente relacionado à inovações tecnológica e institucional, é destacado com o intuito de dar sentido e direção ao processo de crescimento e mudança estrutural necessário para o desenvolvimento sustentável.
\end{abstract}

Palavras-chave: Desenvolvimento econômico. Estratégias de desenvolvimento. Desenvolvimento sustentável. Dissociação de recursos e de impacto.

\section{INTRODUÇÃO}

Desde o final da segunda grande guerra do século passado, diferentes países emergentes adotaram diferentes estratégias de desenvolvimento. Alguns países tiveram estratégias confusas e principalmente não consistentes. Alguns foram mais bem sucedidos do que outros na melhoria da qualidade de vida da sua população. Alguns adotaram mais de uma estratégia no período, como o Brasil e a China. A atual crise financeira internacional tem gerado um interessante debate na literatura internacional sobre a conveniência e mesmo a viabilidade de diferentes estratégias para os países emergentes seguirem no futuro. O objetivo deste artigo é analisar alguns pontos envolvidos nesta temática. O artigo está construído da seguinte forma: após esta

\footnotetext{
* Doutor em Economia pela Universidade de Londres. É professor associado III do Departamento de Economia da Universidade Federal do Paraná. Endereço eletrônico: scatolin@ufpr.br.

** Oceanógrafo, habilitado em Gestão Ambiental Costeira, pela Universidade Federal do Paraná. Endereço eletrônico:misagerco@gmail.com.
} 
introdução, as principais estratégias de desenvolvimento adotadas pelos países em desenvolvimento no período entre a segunda grande guerra e a crise de 2008 são discutidas. Na seção seguinte, os elementos centrais de uma nova estratégia de desenvolvimento sustentável para países de industrialização retardatária são considerados. Finalmente, na conclusão os principais aspectos levantados são destacados. O ponto central do artigo é o de destacar a necessidade de uma mudança nas estratégias de desenvolvimento dos países emergentes, tendo como característica central um processo virtuoso de avanço na agregação de valor dos seus bens produzidos e uma mudança estrutural na direção do desenvolvimento sustentável.

\section{AS ESTRATÉGIAS DE DESENVOLVIMENTO NO PÓS-SEGUNDA GUERRA ${ }^{1}$}

Podem-se identificar pelo menos quatro diferentes estratégias de desenvolvimento adotadas pelos países emergentes ao longo da segunda metade do século XX. A primeira estratégia tem sido a Neoliberal, que se concentra no aumento da eficiência dos sinais de mercado como guia para a melhoria da alocação de recursos econômicos (GRIFFIN, 1999, p. 26). Os instrumentos utilizados se concentram na política fiscal, cambial e monetária e nas reformas econômicas. O regime de metas de inflação e as políticas conhecidas como Consenso de Washington são uma evolução nesta concepção e têm sido parte integrante deste receituário nas últimas décadas. Esta estratégia está profundamente enraizada na tradição da microeconomia neoclássica (deixar o mercado funcionar corretamente com a remoção de distorções e estabelecendo um conjunto coerente de preços relativos), mas com objetivos macroeconômicos de crescimento de longo prazo (GRIFFIN, 1999, p. 26). O setor privado é o elemento central da estratégia, e representa o setor líder do processo. Ao Estado resta um papel reduzido, criando um ambiente estável, minimizando falhas de mercado com o intuito de permitir o florescimento do setor privado. Os principais objetivos da política econômica são estabilizar os preços e produzir um bom funcionamento do mercado, melhorando assim a alocação de recursos e, consequentemente, aumentando o nível de produto e o padrão de vida da população. A Argentina no final dos anos 70 e anos 90 e o Brasil dos anos 90 e início da ultima década são exemplos de países que seguiram esta estratégia. Uma vertente complementar desta estratégia é a estratégia liberal voltada para fora, que se utiliza de algumas das características da estratégia neoliberal, mas engloba outro elemento importante, que é um papel mais ativo do Estado na condução da política macroeconômica de curto prazo (GRIFFIN, 1999, p. 27). O Estado tem um papel mais intervencionista e está presente na determinação da alocação de recursos, em particular

1 Para uma completa descrição das diferentes estratégias de desenvolvimento adotadas pelos diferentes países antigamente conhecidos como países do terceiro mundo ver especialmente Griffin 1999, capítulo 2. 
utilizando as políticas cambial e as de comércio exterior. Através de compra e venda de divisas, tarifas alfandegárias, barreiras não tarifárias, quotas etc., pretende-se induzir o setor privado a participar mais ativamente na economia mundial. O comércio exterior, com frequência, tem sido o setor líder ou motor do crescimento dentro desta estratégia. O Chile, na América Latina, em alguns momentos tem sido um exemplo na implementação de uma estratégia neoliberal e em outros momentos a estratégia seguiu com a variante do comércio exterior.

A segunda estratégia tem sido a de desenvolvimento via industrialização. A ênfase desta estratégia é na industrialização, com o objetivo de aumentar o produto da economia e com isso melhorar o padrão de vida da população. Diferente da estratégia neoliberal, a ênfase aqui não é no curto prazo, mas sim na aceleração da taxa de crescimento do produto agregado (GRIFFIN, 1999, p. 28). Urbanização e industrialização tendem a caminhar na mesma direção. A intervenção do Estado é deliberada não na direção da alocação eficiente de recursos, mas sim no crescimento da produção de manufaturas e da produção no longo prazo. Normalmente o objetivo desta estratégia tem sido buscado de duas formas distintas: a primeira forma via o crescimento do setor manufatureiro produtor de bens de consumo destinados ao mercado interno e com forte proteção tarifária. O Brasil entre 1950 e 1985 é citado como exemplo desta estratégia, junto com outros países latino-americanos. A abundância de recursos naturais renováveis e não renováveis determinaram a especialização setorial no comércio exterior. A segunda forma de industrialização tem sido a de deliberadamente orientar o setor manufatureiro para as exportações. Inicialmente, os países exportam bens industriais que usam recursos que estes têm em abundância, como mão de obra. Na sequência, quando este excesso de mão de obra se esgota, passam a exportar produtos mais intensivos em capital, como aço e automóveis; e, finalmente, em uma terceira fase, exportam produtos de maior valor agregado e intensivo em conhecimento. Os países do sudeste asiático, como Coreia do Sul e Taiwan desde os anos 60, e o Vietnam e a China mais recentemente (anos 90 em diante), são considerados exemplos de países que perseguiram esta estratégia.

A terceira concepção é a estratégia de desenvolvimento baseada na revolução verde. A estratégia tem como objetivo o crescimento do setor primário (agricultura) e não o crescimento do produto como um todo, como a estratégia anterior. O objetivo é reduzir a pobreza via redução do custo da alimentação e a especialização nos segmentos onde o país dispõe de vantagens comparativas correntes. Países como Filipinas e Bangladesh seguiram este percurso nas décadas seguintes a segunda grande guerra. Uma vertente complementar a esta é a estratégia redistributiva de desenvolvimento (GRIFFIN, 1999, p. 30). A estratégia começa onde a anterior termina, isto é, da agricultura para os demais setores da economia. Uma estratégia completa de 
redistribuição atenderia cinco pontos: (I) uma redistribuição inicial de patrimônio; (II) criação de instituições locais, afim de permitir participação à população; (III) pesado investimento em capital humano; (IV) padrão de desenvolvimento intensivo em mão de obra; (V) crescimento sustentável da renda per capita. Sri Lanka no passado e Bolívia e Equador na atualidade seguem esta estratégia.

Finalmente, a quarta estratégia foi a vertente socialista de desenvolvimento. O Estado era o agente central da estratégia, com pouca participação da iniciativa privada. A grande empresa estatal deveria liderar o processo de acumulação de capital e crescimento. Pequenas e médias empresas poderiam ser constituídas por cooperativas e com controle social. Países socialistas adotaram diferentes vertentes desta estratégia, como a China até 1979 e a Coreia do Norte até o presente (GRIFFIN, 1999, p. 31). Na América Latina, o caso cubano é o exemplo desta estratégia.

Uma análise comparativa destas diferentes estratégias até a crise de 2008 deveria começar por comparar o padrão de vida da população antes da implementação da estratégia escolhida (T0) com os resultados da implementação da estratégia em um segundo momento (T1). Não é o caso de realizar aqui este exercício, mas se assim o fizesse, a supremacia da estratégia de desenvolvimento baseada na industrialização via promoção de exportações de manufaturas, dos países do sudeste asiático claramente apareceria como superior em relação as demais no período $^{2}$. Um processo de crescimento industrial e mudança de estrutura produtiva, orientado ao resto do mundo via incorporação de progresso técnico, vai aumentando paulatinamente o valor adicionado da produção local. Um círculo virtuoso de crescimento e melhoria da qualidade de vida da população, baseado no crescimento das exportações de manufaturas e no investimento, do ponto de vista da demanda agregada, e nas inovações e na qualificação da mão de obra, do lado da oferta. Mas aqui o que interessa destacar não são tanto os elementos positivos da estratégia de promoção de manufaturas do pós-segunda guerra, mas sim a ausência de alguns elementos essenciais para o desenvolvimento presente e futuro. Nenhuma das estratégias perseguidas priorizou a preservação do meio ambiente e a sua sustentabilidade. Pelo contrário, as diferentes estratégias utilizaram de maneira intensiva o uso de recursos não renováveis, contribuindo juntamente com os países desenvolvidos para a crise ambiental presente. Na próxima seção, alguns elementos para uma estratégia de desenvolvimento sustentável são discutidos.

2 Para uma análise comparativa entre a segunda guerra e o final da década de 80 ver Griffin, 1999. Para o período recente, ver especialmente os indicadores de desenvolvimento do World Bank. 


\section{A TRANSIÇÃO PARA UMA ESTRATÉGIA DE DESENVOLVIMENTO SUSTEN- TÁVEL}

O ponto de partida para a discussão de uma nova estratégia de desenvolvimento deve ser o debate de uma estratégia que avance no processo de crescimento e mudança estrutural, isto é, que proporcione uma mudança qualitativa e quantitativa de uma determinada estrutura econômica, social e política e que incorpore a dimensão ambiental no centro desta nova estratégia. As inovações verdes e os investimentos necessários são os elementos centrais para a transição entre uma estrutura atual para uma nova estrutura baseada em uma economia verde.

O conceito da economia verde ${ }^{3}$ busca analisar a estrutura produtiva de uma economia a partir da utilização dos seus recursos e do resultado da intervenção humana sobre o meio ambiente. Busca uma reinvenção do processo de produção e de consumo vigente na direção de uma nova estrutura produtiva que possa conciliar o crescimento da qualidade de vida da geração atual com a qualidade de vida das gerações futuras. Este novo termo complementa o conceito de desenvolvimento sustentável, pois implica numa forma direta de transição de uma estrutura produtiva atual (economia marrom), poluidora e intensiva em recursos naturais não renováveis, para uma nova estrutura produtiva caracterizada pelo uso menos intensivo de recursos naturais não renováveis, de um lado, e pela geração de menor quantidade de externalidades negativas (poluição) no meio ambiente, de outro. Para explicitar melhor este ponto, dois outros conceitos são essenciais. Primeiramente, o conceito de dissociação (decoupling), elaborado pelas Nações Unidas (UNEP, 2011a), e o conceito de salto à frente (leapfrogging).

O conceito de dissociação (decoupling) surge como um dos pilares desta nova estrutura produtiva em gestação (economia verde), e implica na dissociação entre o crescimento econômico (PIB) ou da melhoria da qualidade de vida da população e a utilização dos recursos naturais não renováveis como elemento central na geração de riqueza e bem-estar na economia global. Deve-se entender o termo dissociação se manifestando em duas formas básicas. De um lado, a abordagem de que é possível aumentar a produção de bens e serviços e/ou a qualidade de vida com a diminuição relativa da exploração dos recursos naturais não renováveis, através da progressiva redução da utilização dos recursos físicos não renováveis por unidade de produto. Este tipo de dissociação é conhecida como dissociação dos recursos (resource decoupling, Gráfico 1, parte de cima).

3 Ver OECD 2011, UNEP 2011a e UNEP 2011b. 
GRÁFICO 1 - MODELO DE CRESCIMENTO VERDE

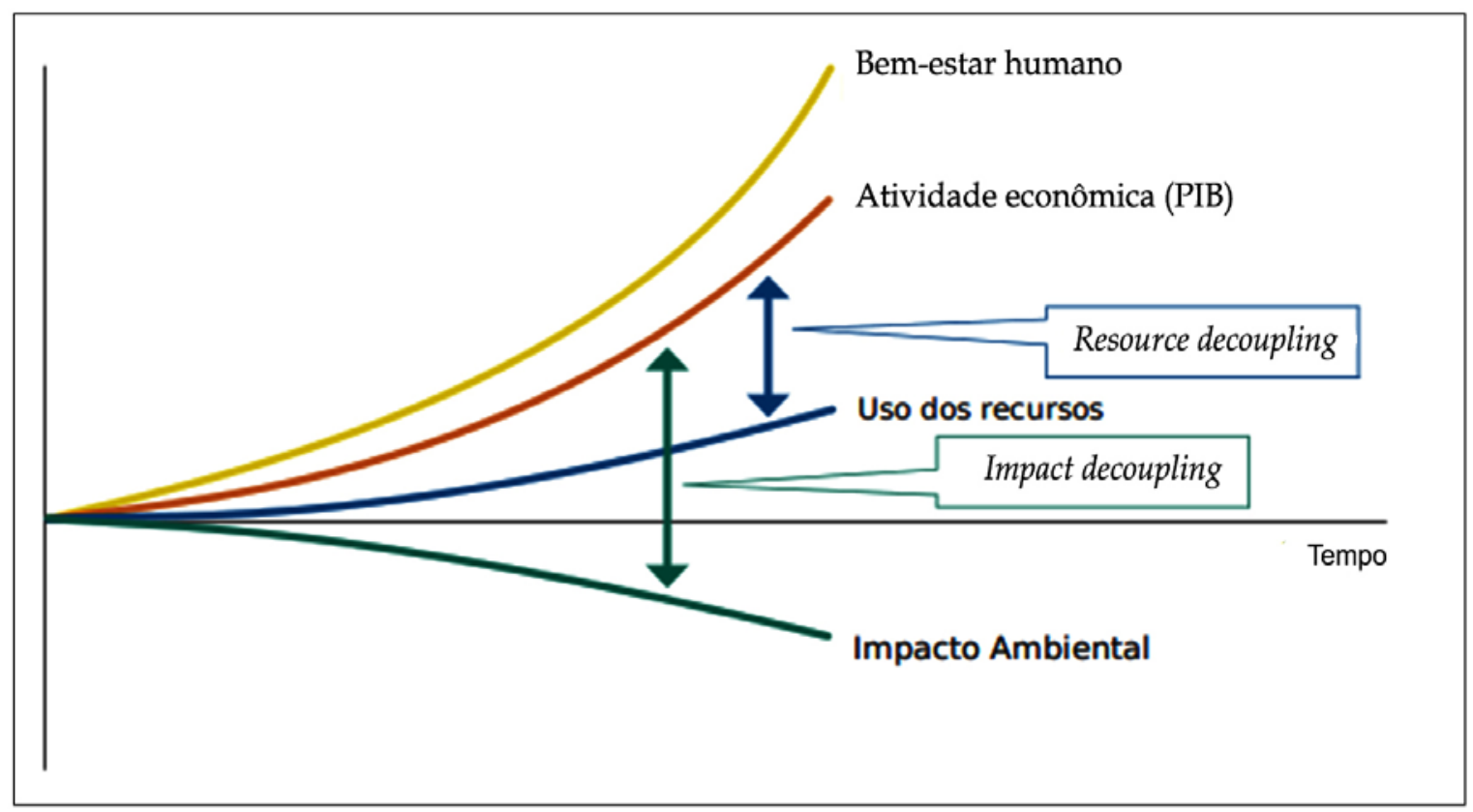

FONTE: UNEP, 2011a.

Por outro lado, a geração de externalidades negativas oriundas da produção econômica e o subsequente impacto ambiental podem ser reduzidos com a implantação de inovações voltadas ao controle da externalidade e pela substituição de processos produtivos ineficientes por novos processos. Este tipo de avanço é chamado de dissociação do impacto ambiental (impact decoupling). O exemplo está ilustrado no Gráfico 1, na parte de baixo. Esta nova forma de raciocínio sobre mudança estrutural e sustentabilidade procura relacionar a ideia geral de que as diferentes estratégias de desenvolvimento adotadas pelos diferentes países em desenvolvimento não têm sido sustentáveis pelas próprias evidências e consequências que a crise mundial trouxe à tona. Estas duas curvas, genericamente chamadas de dissociação (decoupling), apresentam soluções alcançáveis para atender demandas globais futuras de produção de bens e serviços. Este conceito vem sendo implementado em algumas experiências no mundo, como na Coreia do Sul, Suécia etc., onde investimentos na economia verde chegam ao equivalente a $2 \%$ do PIB, tornando-se uma referência na promoção da qualidade de vida e na redução de emissões dos gases do efeito estufa.

Um segundo conceito relevante e que adquire nova dimensão na direção da economia verde para os países em desenvolvimento é o conceito de salto à frente (leapfrogging). Este termo, muito utilizado na economia da inovação (criação destruidora), estava associado inicialmente à ideia de salto tecnológico de uma empresa à liderança tecnológica. Esse salto à liderança do mercado através da implantação de avanços tecnológicos, muitas vezes difíceis e onerosos, in- 
dica um novo patamar de mercado a ser perseguido pelas demais empresas a partir desta nova realidade. Mais recentemente, este conceito está sendo utilizado pela teoria do desenvolvimento com o sentido de que países em desenvolvimento podem abandonar tecnologias velhas do velho paradigma da metal-mecânica do passado e dar um salto à frente evitando as tecnologias e as trajetórias poluidoras adotadas pelos países avançados no passado. Ao invés da implantação de uma estrutura produtiva baseada no uso intensivo de recursos naturais não renováveis, como o petróleo e outras energias não renováveis, os países em desenvolvimento poderiam dar um salto à frente na direção de uma estrutura produtiva baseada na energia renovável, como a energia solar, a eólica e a hidráulica, por exemplo.

Os países emergentes que já desfrutam de uma base produtiva mais diversificada com um padrão de renda mais elevado, deverão também alterar suas formas de vida no mesmo sentido em que os países ricos hoje terão que proceder. Mas aqui a dimensão social necessita incorporar as maiorias populacionais hoje ainda marginalizadas, inserindo-as nestes novos padrões de consumo e qualidade de vida. Somente esta última perspectiva em escala mundial significa incorporar cerca de 2,5 bilhões de pessoas a estes novos padrões de consumo e formas de vida com novos impactos ambientais, que podem e devem diminuir relativamente ao longo do tempo. Mas nenhuma população dos países emergentes aceitaria que metas de desenvolvimento sustentável possam significar abandono de melhorias na qualidade de vida para continuar a garantir irracionais desperdícios de recursos implícitos nos padrões de consumo dos países mais desenvolvidos na atualidade. Desse modo, torna-se imperativo que se realize a transição de uma economia marrom para uma economia mais verde a nível global, produzindo de forma eficiente e buscando reutilizar, reciclar e reduzir matérias-primas, sem comprometer a demanda de uma população mundial em constante crescimento, que almeja melhoria na qualidade de vida.

\section{CONCLUSÃO}

Com relação às diferentes estratégias de desenvolvimento para os países emergentes é possível destacar alguns pontos. Países que tem um projeto de nação, isto é, possuem uma estratégia de desenvolvimento consistente, administram sua taxa de câmbio conforme seus objetivos estratégicos. Isto é, nas estratégias de desenvolvimento onde o crescimento do produto no longo prazo é a prioridade da política econômica, como nas experiências de industrialização do pós-guerra, a taxa de câmbio não é uma variável a ser deixada ao livre jogo da especulação. Até mesmo países como a Suíça, que já atingiram um elevado nível de desenvolvimento sustentável, recentemente passaram a administrar sua taxa de câmbio para atender seus interesses de longo prazo. 
Os países em desenvolvimento precisam priorizar, além do câmbio, variáveis como a inovação, o investimento e a educação, na direção da mudança estrutural desejada. São estas variáveis que as evidências empíricas consideram relevantes no processo de crescimento e mudança estrutural das nações. Cabe ressaltar que as inovações necessárias para o processo de mudança estrutural na direção de uma nova estrutura produtiva verde não são apenas inovações de produto e de processo, mas também organizacionais e institucionais, onde se buscam novas formas de gestão da sociedade, com novas obrigações contratuais, precauções e mesmo obrigações individuais.

Em síntese, uma nova estratégia de desenvolvimento sustentável para um país significa repensar e reinventar a forma de convivência da sociedade como um todo e sua inserção autônoma na economia global. Planejamento estratégico é essencial e indispensável para os países emergentes avançarem e darem este salto à frente necessário.

\section{REFERÊNCIAS}

BIELSCHOWSKY, R. Pensamento econômico brasileiro: o ciclo ideológico do desenvolvimentismo. Rio de Janeiro: IPEA, 1998.

EICHENGREEN, B. Globalizing capital: a history of the international monetary system. 2. ed. Pinceton: Princeton University Press, 2008.

ESTERLY, W. O espetáculo do crescimento. Rio de Janeiro: Ediouro, 2004.

GHG Protocol Brasil. Disponível: <http://www.ghgprotocolbrasil.com.br/>.

GRIFFIN, K. Alternatives strategies for economic development. 2. ed. London: Macmilan Press, 1999.

JONES, H. G. Modernas teorias do crescimento econômico: uma introdução. São Paulo: Atlas, 1999.

OECD. Towards green growth - a summary for policy makers, 2011.

SCATOLIN, F. D. Structural change and growth: the development of brazilian agroindustrial system. Tese (Doutorado em Economia) - University of London, Londres, 1994.

STIGLITZ, J. E. Economics of the public sector. New York: W. W. Norton, 1999.

THIRLWALL, A. P. A natureza do crescimento econômico: uma referência alternativa para compreender o desenvolvimento das nações. Brasília: IPEA, 2005.

UNEP. International Resource Panel. Decoupling natural resource use and environmental impacts from economic growth, 2011.

UNEP - Towards a green economy: pathways to sustainable development and poverty eradication - a synthesis for policy makers. Disponível em: <www.unep.org/greeneconomy>.

WORLD Bank - Indicadores de desenvolvimento. Disponível em: <www.worldbank.org/>. 